\title{
Is the boundary of fun redefined in a mixed-reality serious game?
}

Antoine Taly (taly@ibpc.fr)

Laboratoire de Biochimie Théorique, UPR9080, Institut de Biologie Physico Chimique

Category: The study best fit with the Hybridisation theme (i.e. mix between video games and toys) and additionally to the Toys \& education theme.

\section{Abstract}

Considering Games with the broad definition proposed by Juul (Juul, 2010), consequences outside of the magic circle can be negotiated. This definition opens up the possibility to define serious games, games developed with an utilitarian goal in mind, in addition to fun. The entertaining and utilitarian objectives may however be contradictory, leading serious games to be, more often than not, less than optimal in at least one of the two dimensions. Another way to play with the boundaries of games is to consider pervasive games, which include alternate reality games, and crossmedia games (Montola, 2005).

We question here the limit between game, play and toy in the context of a mixed reality serious game. 'Pangu' is a game designed for bachelor students, with biochemistry as the utilitarian objective, and the origin of life as a game theme. The students are asked to play the game on their smartphone, which in turn ask them to build molecules with a tangible balls-andsticks model typically used in chemistry classes. Pictures taken from the models allow users to 'scan' these models and progress in the game.

The use of the game was observed in four opportunities. An unanticipated observation is that, in addition to expected behaviors, some students used briefly the models like a toy rather than in the context of the game. It is therefore tempting to speculate that the pervasive nature of the game is blurring the game/non game boundary and, in the context of this serious game, opens a door for fun.

\section{Keywords}

Serious game; free play; hybrid game

\section{Introduction}

Some situations can be intuitively identified as play without any further analysis. Many situations are, however, more ambiguous and require a definition to be correctly characterized. Interestingly, these situations allow us to test our understanding (and associated definitions).

To set up a game definition we follow Deterding and colleagues: "Whereas paidia (or "playing") denotes a more freeform, expressive, improvisational, even "tumultuous" recombination of behaviors and meanings, ludus (or "gaming") captures playing structured by rules and competitive strife toward goals. Along those lines, classic definitions in game studies state that gaming and games - in contrast to playing and toys - are characterized by explicit rule systems and the competition or strife of actors in those systems towards discrete goals or outcomes [42,60]." (Deterding, 2011).

Serious game have been defined by Sande Chen and David Michael as a game "in which education (in its various forms) is the primary goal rather than entertainment" (Michael, 2005). Interestingly, it has been argued that videogames have properties that make them adequate learning platforms (Gee, 2003). However, as noted by Brougère, this definition forces one to play with games limits/definitions (Brougère, 2012). Indeed, the expression serious game is often considered as an oxymore (Djaouti, 2011). This implies that a game can only be for fun. However, 
one intriguing observation is that play is largely distributed in the animal kingdom (Burghardt, 2005). Given that play involves a significant investment of resources (time, energy, etc), its maintenance during evolution suggests that play has compensatory (positive) effects on animals. Therefore, although individuals engage in play only for their personal reward (fun), it can be argued that a positive impact, besides fun, could be the reason for play to have been selected during evolution. It is impossible to make a definitive demonstration of that positive link but at least it strongly suggest that benefits of play cannot be excluded. Therefore, we should be able to consider serious games, whether they have been developed for fun only or not.

Among videogames, in the field of science, a striking example is the game Foldit (Cooper 2010, Good 2011). The Foldit project is a datagame (Alvarez 2018). It presents itself as an online 3D jigsaw puzzle in which players are invited to shake and wiggle the 3D structure of proteins to find their most stable conformations (Cooper 2010). Interestingly, Foldit has been rapidly used for teaching with great success (Franco 2012).

It therefore appears important for our project to adopt a definition of games that encompass serious games. To do so I decided to use the definition coined by Juul (Juul 2010). The game definition proposed has 6 points: "1) Rules: Games are rule-based. 2) Variable, quantifiable outcome: Games have variable, quantifiable outcomes. 3) Value assigned to possible outcomes: That the different potential outcomes of the game are assigned different values, some being positive, some being negative. 4) Player effort: That the player invests effort in order to influence the outcome. 5) Player attached to outcome: That the players are attached to the outcomes of the game in the sense that a player will be the winner and "happy" if a positive outcome happens, and loser and "unhappy" if a negative outcome happens. 6) Negotiable consequences: The same game [set of rules] can be played with or without real-life consequences." This definition opens up the possibility to define serious games, games developed with an utilitarian goal in mind, in addition to fun.

The entertaining and utilitarian objectives may however be contradictory, leading serious games to be, more often than not, less than optimal in at least one of the two dimensions (Baaden, 2017). Indeed, Brougère shows that there is an inherent tension between the two natures of this dual object (Brougère, 2012). The tension being more or less depending on the cases. Coming back to the definition of a game given by Juul (see above) we need to take into account the diversity of players. A game can be considered a game even if not all players enjoy it, as noted by Triclot (Triclot, 2017). In the case of a game used for another purpose than fun it allows to consider it to still be a game even if some users are constrained to use it and, as a consequence, do not have fun.

To analyse properly the situation it will be necessary to shift from an analysis based on the game to an analysis based on play (Triclot, 2013). Play will be considered here at an individual level. That will allow us to analyze test situations and identify the emergence of play in the game. To do so we need to be able to identify play behavior in the context of the serious game. We will use the definition of play coined by Burghardt which is based on five criteria (Burghardt, 2011): 1) not fully functional in the form or context in which it is expressed; 2) spontaneous, voluntary, intentional, pleasurable; rewarding, reinforcing or autotelic; 3) differs from strictly functional expressions of behavior; 4) performed repeatedly in a similar, but not rigidly stereotyped, form; 5) behavior initiated when the animal is adequately fed, clothed, healthy, and not under stress. It should be noted here that the fourth criterium on repetition might be an issue in our analysis given the limited cumulated observation time (see below).

The consequence is that we should analyse a series of use of a game and look for the presence of play. In order to facilitate the analysis I propose to also change scale, and look at the 
tension between serious and fun at the game element level. More specifically the focus of our attention is on tangible elements of the games.

The question that can be asked here is how the presence of a tangible element can alter the tension between play and non-play in a serious game. Does the tangible element of the game allow play to emerge in a serious game? Is it favorable to the serious objective or detrimental?

\section{The studied game}

We are using here the app 'Pangu, a short story of life' as available in the Google play app store (Baaden, 2017). The students are asked to download the app and are provided with molecular ball and stick kits. 'Pangu' is a game designed for bachelor students, with biochemistry as the utilitarian objective, and the origin of life as a game theme. The students are asked to play the game on their smartphone, which in turn ask them to build molecules with a tangible balls-andsticks model typically used in chemistry classes (Figure 1). Pictures taken from the models allow users to 'scan' these models and progress in the game. To progress in the game the students need to build molecules and take a picture of them to 'import' them in the numeric part of the game, if they have built the correct molecule.

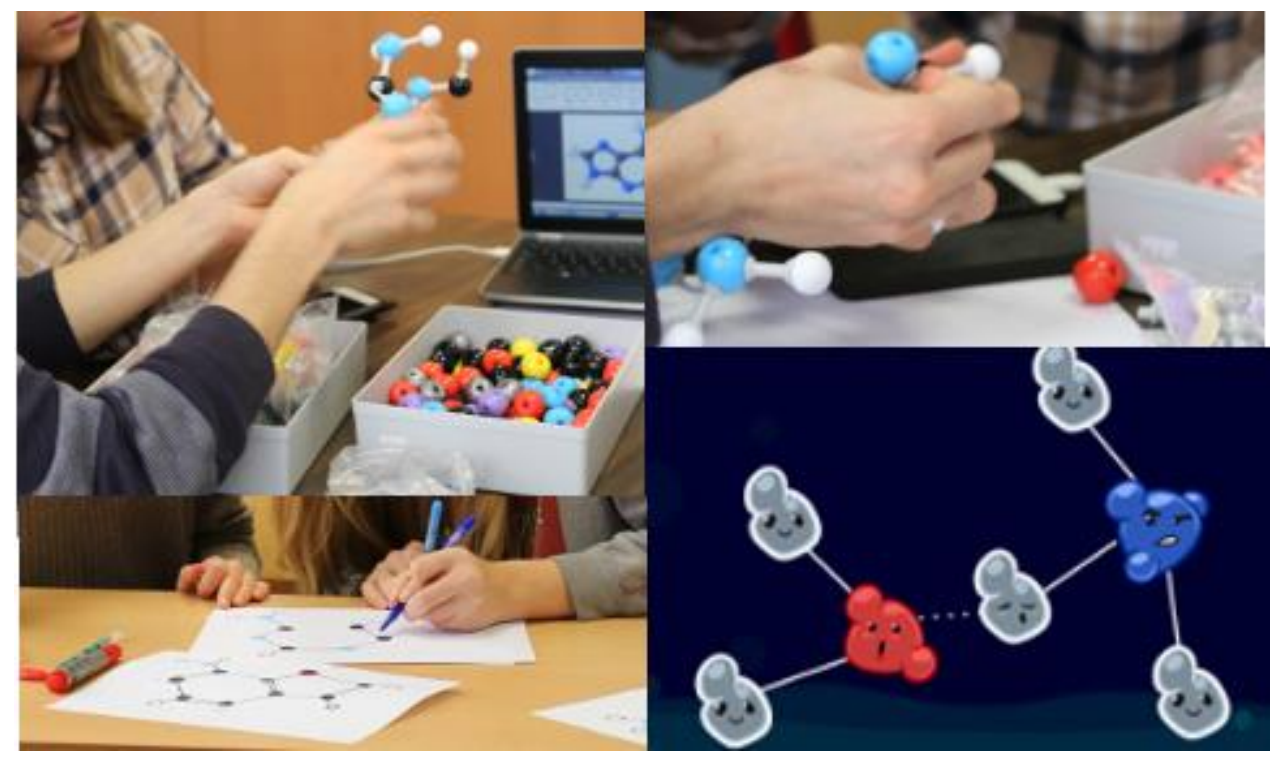

Figure 1. 'Pangu, a short story of life' game. Top left: students playing the game. Top right: students building molecules. Bottom left: students drawing molecules. Bottom right: representation of molecules in the app.

Without going into an exhaustive description of the game some elements need to be described to understand the following analysis. Inspired by the concept of gameplay bricks (Djaouti, 2008) we will describe key elements/properties of the game. Many element have been introduced for ditactic reasons, and can be playful or not. The other elements are either: i) technical elements allowing the progression in the game or interaction with the player; ii) "Gamification", i.e; the use of game design elements in non-game contexts (Deterding, 2011). The various elements can be therefore broadly classified as follows:

\begin{tabular}{|l|l|l|}
\hline & Didactic & Non didactic \\
\hline Playful & Playful didactic activity & Gamification element \\
\hline
\end{tabular}




\begin{tabular}{|l|l|l|}
\hline Not playful & exercise & Technical element \\
\hline
\end{tabular}

The most straightforward category is that of non didactic elements. In Pangu a few elements were included in the app because their properties had been anticipated to potentially increase the playfulness of the game. To analyse elements of playfulness we use the game dimensions defined by Garris and coworkers: Fantasy; Rules/Goals; Sensory Stimuli; Challenge; Mystery and Control (Garris, 2002). We also refer to more broad system of 22 categories defined by Lucero and coworkers: Captivation, Challenge, Competition, Completion, Control, Cruelty, Discovery, Eroticism, Exploration, Expression, Fantasy, Fellowship, Humor, Nurture, Relaxation, Sensation, Simulation, Submission, Subversion, Suffering, Sympathy, Thrill (Lucero, 2010). The following gamification elements can be described:

- The atoms are represented with some 'face' associated with a different character for each element (Figure 1). This is obviously orthogonal to any physicochemical consideration but rather relates to the categories Fantasy (Garris) / Humor (Lucero). This representation can also be assimilated to a rhetoric trait of the game and more specifically with a cute factor (Brougère, 2013)

- Other art design, i.e. Music and success Animations, correspond to Sensory Stimuli (Garris), sensation (Lucero).

- The players can make a collection of molecules which relates to Rules/Goals (Garris) and completion (Lucero).

Didactic elements are more interesting in the context of this manuscript because they are not meant to be playful but might be (see below). In particular, the tangible construction material was introduced for didactic reasons, because it encodes geometric constraints of molecular construction. Indeed, it has been observed that understanding of atoms, molecules and chemical bonds can be improved with discussions around varied models/representations (Harrison, 2000). However, the presence of the tangible construction material also relates Pangu to the category of pervasive games, which include alternate reality games, and crossmedia games (Montola, 2005).

\section{Play Analysis/Observations}

The analyses presented below were performed based on the use of the game in similar settings:

- During the rigole workshop (Taly, 2018a) at the FdV bachelor in Paris Descartes University. A playtest was organised to support the development of the game and filmed for communication reasons (Octobre 2017).

- During the rigole workshop at the at the university of Sao Paulo, department of Pharmaceutical sciences in Ribeirao Preto (March 2018).

- During an outreach event (Conference of the European Citizen Science Association in Geneva, June 2018). This can be considered a double blind experiment: i) the event was moderated and recorded by Mrs Gaelle Guérin during her internship with the citizen science program Dito; ii) observations were made a posteriori.

- During the rigole workshop for high-school students at the at Paris Descartes University, department of Pharmaceutical sciences (July 2018).

To answer our questions it is necessary to look for behavior that correspond to the definition of play presented above. Out of the five criteria some of them can probably be considered as always satisfied in our case: i.e. i) the behaviors reported below are spontaneous, satisfying the second criterion; ii) the players are participating voluntarily to a rather ludic 
workshop so the fifth criterion is probably satisfied (one exception will be presented below). We are therefore looking for behaviors that are not funcional, i.e. that cannot be understood in the context of the game. These behaviors should be seen more than once. Below are presented the cases in which players, in addition to expected behaviors, used briefly the tangible material (models or drawings) like a toy rather than in the context of the game.

\section{Manipulation}

The first observation is that some students used a constructed molecule and manipulated it in a manner that cannot be understood in the context of the game, and is therefore interpreted as playful (Figure 2). This behavior was seen twice: i) first during a playtest in Paris towards the end of the game (Figure 2, top); ii) during the workshop in Brazil. It should be noted that in the latter case the student was not at the game stage anymore. The similarity is however suggestive of a repeated behavior, which would lead to interpret it as playful.

A complementary observation occurred during the latest workshop with high school students. One student who was rather reluctant to the game ${ }^{1}$, staying aside of his group. Latter this student played with a molecule spinning it as a top. Interestingly, he then participated in the resolution of the game.

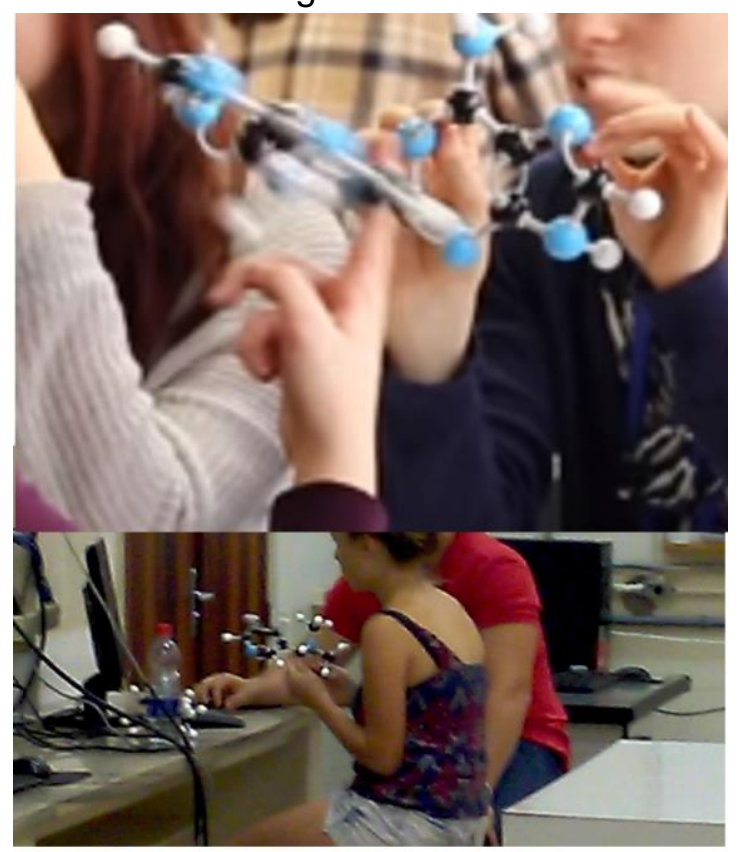

Figure 2. Students using molecule models as a toy. Top: playtest in Paris. Picture from the trailer (Taly, 2018b). Bottom: Brazil workshop. Picture taken from a short movie (Taly, 2018c).

\section{Construction}

The construction material can be used to construct the molecules asked by the game but can also be used to construct any molecule. Players where seen to do so in two occasions:

- First, during the citizen science fair in Geneva a child used the material to construct rather random molecules. The child was with his father and while the father was playing the game he was aside and constructed "molecules" on his own (Figure 3).

- During the latest workshop with high school students some students used the chemistry kit to construct molecules outside of the game. In that case it was apparent that they were perfectly aware that the "molecules" were wrong and they were trying to make a big "monument".

\footnotetext{
${ }^{1}$ Answering a question from a classmate about the interest of the initial context text he explained that "this is the "story"', using quotes for story.
} 


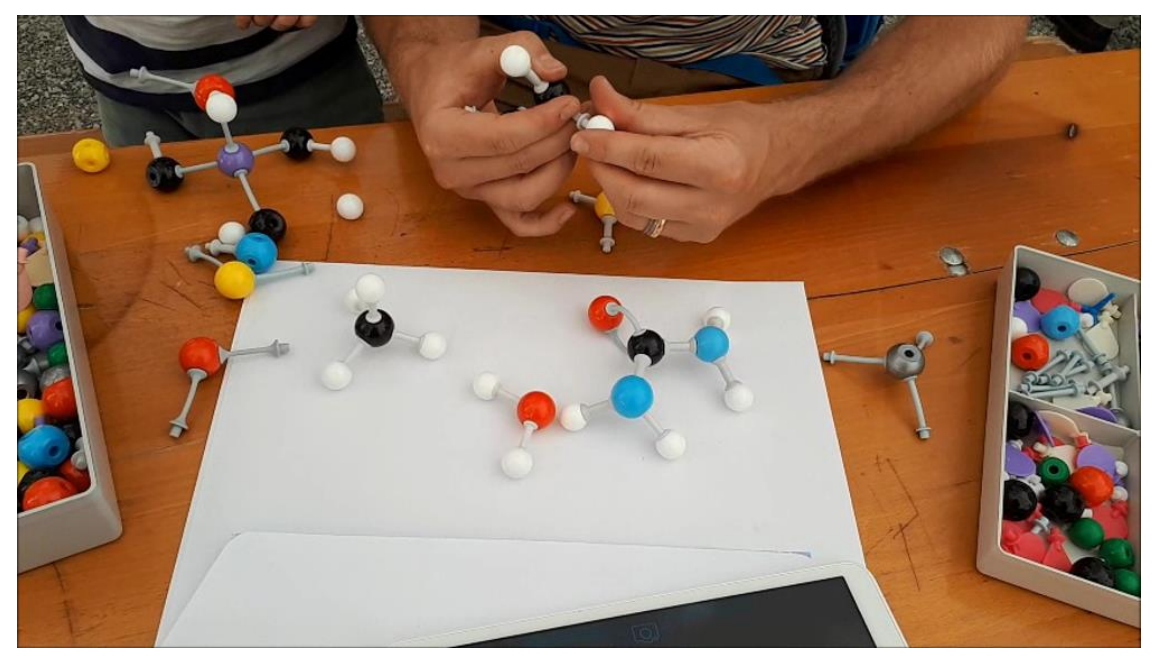

Figure 3. Players using the molecular kit as construction material during a citizen science event in Geneva.

\section{Playing with color codes.}

Another intriguing observation, made both in Paris and in Brazil, is that some groups chose not to use the conventional color code but rather a more personal one. Indeed, the game starts by a calibration phase that has been used by students not to be limited to the conventional color code. Only in one case the students were asked for the reason of changing colors and, in that case, it was because pens were more convenient. However, we cannot exclude, and it is tempting to speculate, that in some instances it was for fun, i.e. in a form of transgression.

\section{Conclusion}

This study suggests that there is room for the emergence of play in a serious game, through the use of tangible material that can be used as a toy. This observation somewhat recapitulates the historical trend for the appearance of free play alongside directed play through construction instructions. Indeed, the same behavior was observed Froebel's Gift construction material: the construction was intended to be constrained by instructions to teacher, but it was observed that free play appeared alongside (Ginoulhiac, 2018).

Another interesting observation is that the play behaviors are not necessarily detrimental to the serious objective. At least in one case it was even observed to serve the serious objective!

\section{Acknowledgements}

Mrs Gaelle Guérin is warming acknowledged for her contribution at the Geneva citizen science fair. I would also like to thank all students/players who participated in the workshops, gave feedback on the game and allowed recording of their play sessions they participated in.

\section{References:}

Alvarez, J. (2018). Datagame: Crowdsourcing, Metrics \& Traces. In Proceedings of the 2nd International Conference on Web Studies (pp. 72-76). ACM.

Baaden, M., Delalande, O., Ferey, N., Pasquali, S., Waldispühl, J., \& Taly, A. (2018). Ten simple rules to create a serious game, illustrated with examples from structural biology.

Brougère, G. (2012). Le jeu peut-il ětre sérieux? Revisiter Jouer/Apprendre en temps de serious game. Australian Journal of French Studies, 49(2), 117-129. 
Brougère, G. (2013). Licensing and the rhetoric of fun: the cute and the cool. Young Consumers, 14(4), 342-350.

Burghardt, G. M. (2005). The genesis of animal play: Testing the limits. Mit Press.

Burghardt, G. M. (2011). Defining and recognizing play. In The Oxford handbook of the development of play.

Cooper, S., Khatib, F., Treuille, A., Barbero, J., Lee, J., Beenen, M., ... \& Popović, Z. (2010). Predicting protein structures with a multiplayer online game. Nature, 466(7307), 756.

Cooper, S., Treuille, A., Barbero, J., Leaver-Fay, A., Tuite, K., Khatib, F., ... \& Popović, Z. (2010, June). The challenge of designing scientific discovery games. In Proceedings of the Fifth international Conference on the Foundations of Digital Games (pp. 40-47). ACM.

Deterding, S., Dixon, D., Khaled, R., \& Nacke, L. (2011). From game design elements to gamefulness: defining gamification. In Proceedings of the 15th international academic MindTrek conference:

Envisioning future media environments (pp. 9-15). ACM.

Djaouti, D., Alvarez, J., Jessel, J. P., Methel, G., \& Molinier, P. (2008). A gameplay definition through videogame classification. International Journal of Computer Games Technology, 2008, 4.

Djaouti, D., Alvarez, J., Jessel, J. P., \& Rampnoux, O. (2011). Origins of serious games. In Serious games and edutainment applications (pp. 25-43). Springer, London.

Franco, J. (2012). Online gaming for understanding folding, interactions, and structure. Journal of Chemical Education, 89(12), 1543-1546.

Garris, R., Ahlers, R., \& Driskell, J. E. (2002). Games, motivation, and learning: A research and practice model. Simulation \& gaming, 33(4), 441-467.

Gee, J. P. (2003). What video games have to teach us about learning and literacy. Computers in Entertainment (CIE), 1(1), 20-20.

Ginoulhiac, M. (2018). Architectural toys, the construction of an education. Présentation, Paris.

Harrison, A. G., \& Treagust, D. F. (2000). Learning about atoms, molecules, and chemical bonds: A case study of multiple-model use in grade 11 chemistry. Science Education, 84(3), 352-381.

Good, B. M., \& Su, A. I. (2011). Games with a scientific purpose. Genome biology, 12(12), 135.

Juul, J. (2010). The game, the player, the world: Looking for a heart of gameness. PLURAIS-Revista

Multidisciplinar, 1(2).

Lucero, A., \& Arrasvuori, J. (2010). PLEX Cards: a source of inspiration when designing for playfulness.

In Proceedings of the 3rd International Conference on Fun and Games (pp. 28-37). ACM.

Michael, D. R., \& Chen, S. L. (2005). Serious games: Games that educate, train, and inform. Muska \& Lipman/Premier-Trade.

Montola, M. (2005, December). Exploring the edge of the magic circle: Defining pervasive games. In Proceedings of DAC (Vol. 1966, p. 103).

Taly, A., Nitti, F., Baaden, M., Pasquali, S. (2018a): Molecular Modeling as the Spark for Active Learning Approaches for Interdisciplinary Biology Teaching. ChemRxiv. Preprint.

https://doi.org/10.26434/chemrxiv.7352120.v1

Taly, A. (2018b) Observation of play with the serious game pangu in Brazil.https://youtu.be/qxZVt8Gg Qs

Taly, A. (2018c) PANGU https://youtu.be/8ZfjphFR7CE

Triclot, M. (2013). Game studies ou études du play?. Une lecture croisée de Jacques Henriot et de Jesper Juul. Sciences du jeu, (1).

Triclot, M. (2017). Philosophie des jeux vidéo. La Découverte. 